\title{
Relationships among estimates of inbreeding depression, dominance and additive variance for linear traits in Holsteins
}

\author{
I Misztal $^{1}$, TJ Lawlor ${ }^{2}, \mathrm{~N}$ Gengler ${ }^{1 *}$ \\ 1 Animal and Dairy Science Department, University of Georgia, Livestock-Poultry \\ Building, Athens, GA 30602; \\ 2 Holstein Association, Brattleboro, VT 05302, USA
}

(Received 26 November 1996; accepted 20 May 1997)

Summary - Estimates of dominance and additive variances were obtained for 14 linear traits. The data included 600678 first parity records on 14 linear traits in Holsteins. The model included management groups, age at calving, additive and dominance effects, and regression on inbreeding percentage. The estimate of the dominance variance was $9.8 \%$ of the phenotypic variance for body depth, $8.0 \%$ for strength, $6.9 \%$ for stature, and was less than $5 \%$ for the remaining traits. The additive variance ranged from $12.2 \%$ for foot angle to $45.3 \%$ for stature. No clear relationship was found between the estimates of dominance and additive variance; larger negative estimates of the inbreeding depression were associated with higher estimates of the dominance variance.

type traits / dominance / inbreeding / variance components

Résumé - Relations entre estimées de dépression de consanguinité, de variances génétiques additives et de dominance pour les caractères de conformation en race Holstein. Des estimées de variances génétiques additives et de dominance ont été obtenues pour 14 caractères de conformation en race Holstein (600678 résultats de première lactation). Le modèle incluait les effets groupes de conduite, l'âge au vêlage, les effets génétiques additifs et de dominance et la régression sur le taux de consanguinité. La variance génétique de dominance a été évaluée à $9,8 \%$ de la variance phénotypique pour la profondeur du corps, à $8,0 \%$ pour la puissance, $6,9 \%$ pour la taille et moins de $5 \%$ pour les autres caractères. La variance génétique additive a varié de 12,2\% pour l'angle du pied à 45,3\% pour la taille. On n'a pas trouvé de relation claire entre les estimées de variance additive et de variance de dominance. On a trouvé que la dépression de consanguinité était d'autant plus forte que l'estimée de variance de dominance était élevée.

caractère de conformation / dominance / consanguinité / composantes de variance

* On leave from Faculté universitaire des sciences agronomiques, B-5030 Gembloux, Belgium 


\section{INTRODUCTION}

Genetic evaluations for farm animals are currently based on the additive model (Henderson, 1985). Dominance effects were ignored for two reasons. First, computations of evaluations with dominance were unfeasible computationally for larger pedigrees. Second, the importance of dominance for the evaluation was not well established; this importance can be rated by the fraction of the dominance variance in the total variance for a given trait. However, good estimates of the dominance variance were not available because of a lack of reliable procedures that would 1) use the animal model to exploit all the dominance information in the data, 2) be resistant to selection bias, and 3) be able to use large and complete data to ensure a low sampling error (Misztal et al, 1995). For comparable accuracy, the estimates of the dominance variance need to be derived from data sets 20-200 times larger than the estimates of the additive variance (Chang, 1988: Hoeschele and VanRaden, 1991). Estimates of dominance variance were obtained in the past either with simplified models (eg, VanRaden et al, 1992), or from small data sets (eg, Rodriguez-Almeida et al, 1995).

Recent developments have made computations with dominance in the model feasible. The discovery of rules to invert the dominance relationship matrix and developments with computing algorithms have made the creation of the mixed model equations with the dominance effect feasible for very large data sets (Hoeschele and VanRaden, 1991). Computing refinements resulted in evaluation with dominance in the model requiring less than twice the memory and computing time of the additive only procedures (Misztal, 1997). The use of method $\mathrm{R}$ has allowed for estimation of variance components for very large data sets (Reverter et al, 1994); method R was shown to be as resistant to several types of selection bias as REML (Snelling, 1994; Kaiser and Golden, 1994).

The feasibility of computations with dominance has created an interest in identifying traits that have a significant dominance variance and thus could benefit from evaluation with dominance in the model. Predictions of the dominance effects could be utilized as special combined abilities in a mating system (DeStefano et al, 1992).

One large source of traits is type traits. Since 1983, the Holstein Association of America has collected data on 14 linear type traits (Thompson et al, 1983). These traits are scored on a unified scale of one to 50, and have a similar phenotypic standard deviation of about 6.0, thus simplifying comparisons among them. Type evaluations are used in an index with production traits to maintain a functional cow. The first goal of this paper was to estimate dominance variances for linear type traits.

A large number of linear traits provides the opportunity for examining relationships between dominance and other effects. As suggested for fitness traits by Falconer (1989), if the gene action is close to overdominant, it is possible that the dominance variance is high for traits with a low additive variance. This leads to a theory that traits with low heritability in the narrow sense are more likely to have a high heritability in the broad sense. In dairy cattle, that theory was supported by studies on production traits (VanRaden et al, 1992) and fertility (Hoeschele, 1991). 
Since type traits have a wide range of different additive variances, the second goal of the paper was to examine this theory in application to type traits.

Because precise estimates of the dominance variance require large data sets, and such sets may not be available, it would be interesting to find out whether the dominance variance can be predicted indirectly. One such possibility is through the use of inbreeding depression, which can be predicted accurately from much smaller data sets. It would be expected that a higher dominance variance would correspond to a higher magnitude of inbreeding depression. The last goal of the paper was to examine the relationship between estimates of dominance variance and inbreeding depression.

\section{MATERIALS AND METHODS}

The data included first-records on the 14 linear traits for the first 600678 Holsteins selected from a data set sorted by herd number and used by the Holstein Association of America for genetic evaluation in July 1995. Additionally, pedigrees of most sires were available. Each trait was analyzed separately using the model

$$
\mathbf{y}+\mathbf{X} \boldsymbol{\beta}+\mathbf{Z b} \boldsymbol{\Delta}+\mathbf{Z a}+\mathbf{Z Q f}+\mathbf{e}
$$

where $\mathbf{y}$ is a $600678 \times 1$ vector of records, $\boldsymbol{\beta}$ is a $23697 \times 1$ vector of management and age at calving effects, $\Delta$ is the coefficient of inbreeding depression, $\mathbf{a}$ is a $732644 \times 1$ vector of additive animal effect, $\mathbf{f}$ is a $1269690 \times 1$ vector of dominance parental effect, $\mathbf{b}$ is a $600678 \times 1$ vector of inbreeding coefficients, and $\mathbf{X}, \mathbf{Z}$ and $\mathbf{Q}$ are matrices or vectors that relate records to respective effects. The variances are

$$
\operatorname{var}\left[\begin{array}{c}
\mathbf{a} \\
\mathbf{f} \\
\mathbf{p} \\
\mathbf{e}
\end{array}\right]=\left[\begin{array}{cccc}
\mathbf{A} \boldsymbol{\sigma}_{\mathrm{a}}^{2} & 0 & 0 & 0 \\
0 & \mathbf{F} \frac{\boldsymbol{\sigma}_{\mathrm{d}}^{2}}{4} & 0 & 0 \\
0 & 0 & \mathbf{I} \boldsymbol{\sigma}_{\mathrm{p}}^{2} & \\
0 & 0 & 0 & \mathbf{I} \boldsymbol{\sigma}_{\mathrm{e}}^{2}
\end{array}\right]
$$

where $\sigma_{\mathrm{a}}^{2}$ is the additive variance and $\boldsymbol{\sigma}_{\mathrm{d}}^{2}$ is the dominance variance, $\mathbf{A}$ is an additive relationship matrix, and $\mathbf{F}$ is a dominance parental relationship matrix as defined in Hoeschele and VanRaden (1991). The average inbreeding for animals was $0.7 \%$ for all animals but increased to $2.4 \%$ for animals born in 1992 ; inbreeding was considered in $\mathbf{A}$ but not in $\mathbf{F}$.

Estimates were obtained by method R as in Misztal (1997). Each trait was analyzed six times, each time with a different subset of the data generated by a random number generator; each subset contained $50 \%$ of the full data set. The convergence criterion was $r_{i}=1 \pm 0.0001$, where $r_{i}$ is the regression for random effect $i$, which corresponds to a numerical error in the estimates of variances of $0.5 \%$ or less of the total variance. Sampling standard deviation of the estimates was calculated as standard deviation of the estimates from different subsamples. 


\section{RESULTS AND DISCUSSION}

Table I presents estimates of inbreeding depressions and variances as well as ratios of the estimates of variances for the 14 traits. All variances are expressed as percentages of the phenotypic variance. While standard deviations in estimates for inbreeding depression among the six samples were no larger than 0.001 and therefore stable, they were up to $0.6 \%$ for the additive variance and up to $1.2 \%$ for the dominance variance. Most of the standard deviations for the additive variance were due to incomplete convergence ( $r_{i}$ differed from 1 by up to 0.0001 ). However, the changes for the dominance variance reflected a limited amount of dominance information in the data and, therefore, relatively large sampling variances. Estimates of the inbreeding depression were small, with the largest magnitude being for body depth at -0.07 . Only two other estimates had a magnitude larger than 0.05: stature and strength. The estimates were positive for several traits, the largest being for udder depth at 0.03 . Positive estimates could result from scale reversal, where lower scores are more desirable. An alternative explanation for udder depth was provided by a reviewer, who suggested that inbred cows milk less so the udders are less full and not as deep.

Table I. Means and standard deviations of estimates of inbreeding depression, additive and dominance variances, and ratios of variances for 14 traits based on six runs of method R.

\begin{tabular}{lcccc}
\hline \multirow{2}{*}{ Trait } & $\begin{array}{c}\text { Inbreeding } \\
\text { depression } \\
( \pm 0.001)\end{array}$ & Additive (1) & Dominance (2) & (2)/(1) \\
\cline { 4 - 5 } & -0.065 & $45.3 \pm 0.3$ & $6.9 \pm 1.2$ & 0.15 \\
Stature & -0.073 & $27.8 \pm 0.5$ & $8.0 \pm 0.7$ & 0.29 \\
Strength & -0.074 & $34.5 \pm 0.3$ & $9.8 \pm 0.7$ & 0.28 \\
Body depth & -0.040 & $23.4 \pm 0.4$ & $5.3 \pm 1.0$ & 0.23 \\
Dairy form & 0.007 & $34.5 \pm 0.6$ & $2.7 \pm 0.7$ & 0.08 \\
Rump angle & -0.048 & $25.4 \pm 0.2$ & $2.5 \pm 0.8$ & 0.10 \\
Thurl width & 0.013 & $18.7 \pm 0.2$ & $3.6 \pm 1.2$ & 0.19 \\
Rear leg set & -0.028 & $12.2 \pm 0.6$ & $2.2 \pm 1.3$ & 0.18 \\
Foot angle & 0.000 & $24.3 \pm 0.5$ & $4.7 \pm 0.7$ & 0.19 \\
Fore udder att & -0.033 & $22.8 \pm 0.4$ & $3.5 \pm 0.7$ & 0.15 \\
Udder height & -0.025 & $19.0 \pm 0.3$ & $3.4 \pm 0.6$ & 0.18 \\
Udder width & -0.006 & $17.9 \pm 0.3$ & $3.1 \pm 0.8$ & 0.17 \\
Udder cleft & 0.034 & $30.1 \pm 0.3$ & $3.6 \pm 0.7$ & 0.12 \\
Udder depth & 0.000 & $25.2 \pm 0.3$ & $2.9 \pm 0.9$ & 0.12 \\
Front teat & & & & \\
Placement & & & & 0.17 \\
\hline Average & & & & \\
\hline
\end{tabular}

The estimates of the additive variance were mostly similar to earlier estimates using first records and the animal model (Misztal et al, 1992). Heritabilities were 0.07 larger for udder height and udder cleft, 0.06 larger for rump angle, and 0.05 larger for udder depth. Heritability was smaller by 0.06 for dairy form; other estimates differed by no more than 0.02 . Larger differences are most likely to be due 
to new age adjustment factors. After age adjustments were included in the model, Lawlor et al (1995) found large changes, particularly for dairy form and udder depth. An increase in the estimate of heritability of 0.05 to 0.20 for stature when age adjustments were fit in the model was found in a study on various dominance models (Misztal et al, 1997).

The estimate of the dominance variance was $8 \%$ of the phenotypic variance or larger for only two traits: body depth and strength. Two other estimates, for stature and dairy form, were above $5 \%$. The remaining ten estimates were below $5 \%$. All traits with larger estimates of dominance were body traits.

The estimates of the dominance variance were within $10-29 \%$ of the estimates of the additive variance, with a mean of $17 \%$. Thus, for type traits, the dominance variance is, on average, six times lower than the additive variance, and only a small part of the total genetic variance.

The inbreeding depression, a linear measure, is more related to standard deviation, a linear measure, than to variance, a quadratic measure. Therefore, tests on relationships between the inbreeding depression and the dominance variance involved estimates of the dominance standard deviation. Table II shows estimates of the phenotypic and dominance standard deviations and the ratio of the estimates of inbreeding depression to dominance standard deviation. In absolute terms, the average ratio of estimates of inbreeding depression per $1 \%$ of inbreeding to estimates of dominance standard deviation was $2.32 \%$.

Table II. Estimates of phenotypic ${ }^{\mathrm{a}}$ and dominance standard deviation, and ratios of estimates of inbreeding depression to estimates of dominance standard deviations for 14 traits.

\begin{tabular}{|c|c|c|c|}
\hline \multirow{2}{*}{ Trait } & \multicolumn{2}{|c|}{ Standard deviation } & \multirow{2}{*}{$\begin{array}{c}\text { Inbreeding } \\
\text { depression/dominance } \\
S D \\
(\%)\end{array}$} \\
\hline & Phenotypic & Dominance & \\
\hline Stature & 7.62 & 2.00 & -3.25 \\
\hline Strength & 6.84 & 1.93 & -3.78 \\
\hline Body depth & 6.93 & 2.17 & -3.41 \\
\hline Dairy form & 6.92 & 1.59 & -2.52 \\
\hline Rump angle & 4.89 & 0.80 & 0.88 \\
\hline Thurl width & 6.67 & 1.05 & -4.57 \\
\hline Rear leg set & 6.33 & 1.20 & 1.08 \\
\hline Foot angle & 5.88 & 0.87 & -3.22 \\
\hline Fore udder att & 6.76 & 1.46 & 0.00 \\
\hline Udder height & 6.83 & 1.27 & -2.60 \\
\hline Udder width & 6.73 & 1.24 & -2.02 \\
\hline Udder cleft & 5.28 & 0.93 & -0.65 \\
\hline Udder depth & 4.03 & 0.76 & 4.47 \\
\hline Front teat & 5.73 & 0.98 & 0.00 \\
\hline Placement & & & \\
\hline $\begin{array}{l}\text { Average of } \\
\text { absolute values }\end{array}$ & 6.25 & 1.30 & 2.32 \\
\hline
\end{tabular}

${ }^{a}$ From Misztal et al, 1992. 
Figure 1 plots estimates of the inbreeding depressions against those of the dominance standard deviations. Larger inbreeding depressions were generally associated with larger dominance variances. All positive estimates of inbreeding depression are associated with low estimates of dominance variance. On average, the dominance standard deviation could be predicted as 1.03-10.94 $\times$ inbreeding depression, with an $R^{2}=0.63$ (table III). Thus, the prediction accuracy is moderate.

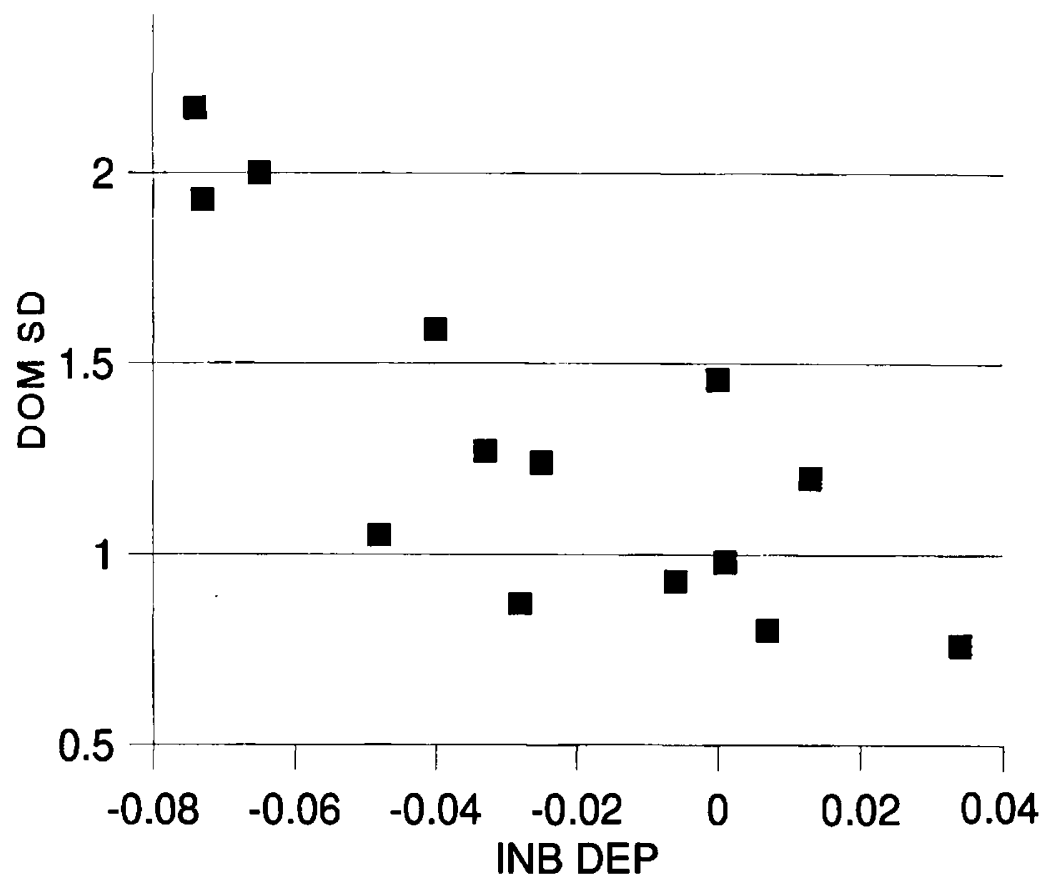

Fig 1. Mean estimates of the inbreeding depression (INB DEP) and the dominance (DOM) variances for the 14 linear traits.

Table III. Results from regressions of the estimates of dominance variance on additive variance and of dominance standard deviation on inbreeding depression.

\begin{tabular}{|c|c|c|c|c|}
\hline $\begin{array}{l}\text { Dependent } \\
\text { variable }\end{array}$ & $\begin{array}{c}\text { Independent } \\
\text { variable }\end{array}$ & Intercept & Slope & $\mathrm{R}^{2}$ \\
\hline Dominance variance & Additive variance & 0.52 & $0.15^{*}$ & 0.31 \\
\hline Dominance SD & $\begin{array}{l}\text { Inbreeding } \\
\text { Depression }\end{array}$ & $1.03^{* *}$ & $-10.94^{* *}$ & 0.63 \\
\hline
\end{tabular}

* Significant at the 0.05 level; ${ }^{* *}$ significant at the 0.01 level.

Figure 2 plots estimates of the dominance variance against those of the additive variance. On average, the estimates of the dominance variance increase slightly with increasing additive variance. The regression of the estimates of dominance 


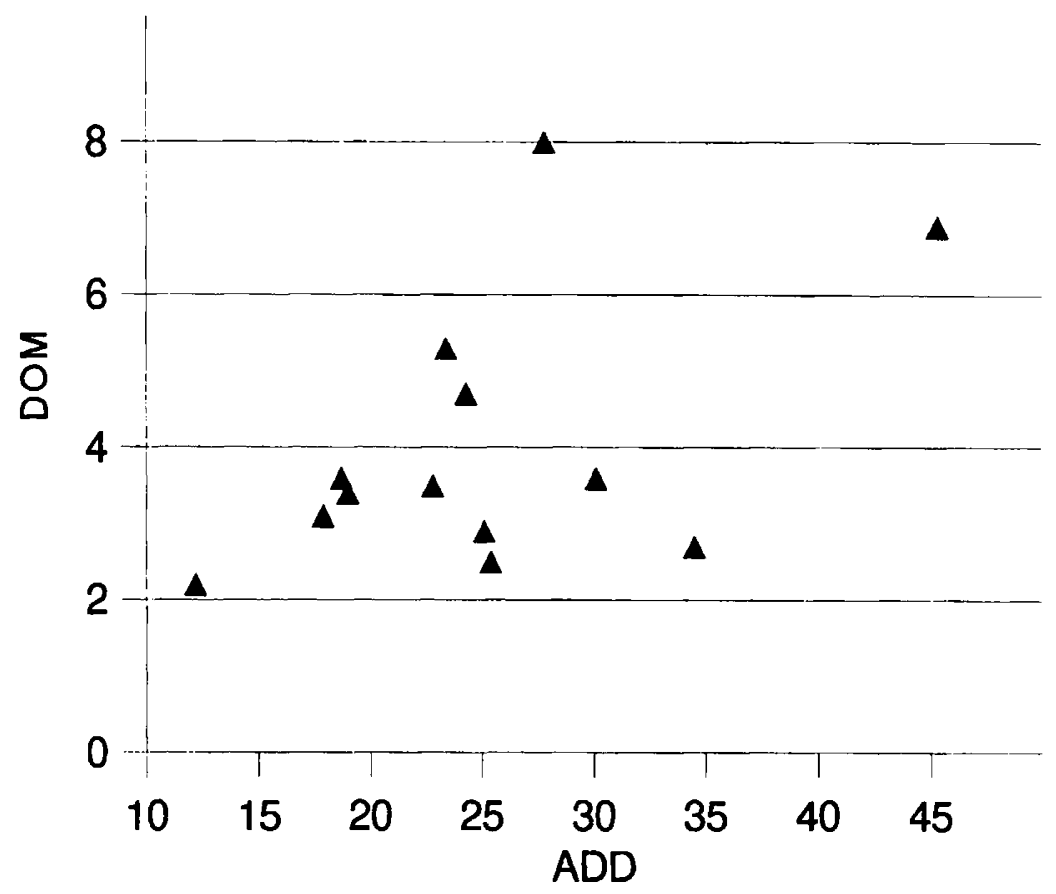

Fig 2. Mean estimates of the additive (ADD) and dominance (DOM) variances for the 14 linear traits.

on additive variances is significant, but has a low $R^{2}$ of 0.31 (table III). Higher estimates of the additive variance generally corresponded to higher estimates of the dominance variance. Thus, the hypothesis that traits with low heritability in the narrow sense are more likely to have a high heritability in the broad sense cannot be confirmed for type traits.

Some of the less conclusive results of this study could be due to the use of an insufficiently large data set. First, many full sibs obtained through embryo transfer are in different herds, and many of them have not been selected in the data set. Subsequently, the 'dominance content' in the data was small and the sampling variance of the dominance estimates was high. Second, inbreeding was calculated without considering the missing pedigrees as in VanRaden (1992). Also most pedigrees of females born prior to 1980 were missing. Subsequently inbreeding depression was underestimated.

In conclusion, the estimates of the dominance variance for type traits are medium for some traits and small for most. Larger negative estimates of the inbreeding depressions were associated with higher estimates of the dominance variance. Larger estimates of dominance variances were generally associated with higher additive variances, but that association was weak. 


\section{ACKNOWLEDGMENTS}

Helpful comments by Keith Bertrand, Matt Culbertson and the two anonymous reviewers are greatfully appreciated. Ignacy Misztal acknowledges the financial support of the Holstein Association of America. Nicolas Gengler, who is Chargé de Recherches of the Fonds National de la Recherche Scientifique, Belgium, acknowledges its financial support. Partial computing support was by the National Center for Supercomputing Applications.

\section{REFERENCES}

Chang HA (1988) Studies on estimation of genetic variances under non-additive gene action. Ph D dissertation, University of Illinois, Urbana, USA

DeStefano AL, Höschele I (1992) Utilization of dominance variance through mate allocation strategies. J Dairy Sci 75, 1680-1690

Falconer DS (1989) Introduction to Quantitative Genetics, 3rd ed. Longman, Burnt Mill, Harlow

Henderson CR (1985) Best linear unbiased prediction of nonadditive genetic merits in noninbred populations. J Anim Sci 60, 111-117

Hoeschele I, VanRaden PM (1991) Rapid inversion of dominance relationship matrices for noninbred populations by including sire by dam subclass effects. J Dairy Sci 74, $557-569$

Hoeschele I (1991) Additive and nonadditive genetic variance in female fertility of Holsteins. J Dairy Sci 74, 1743-1752

Kaiser CJ, Golden BL (1994) Heritability estimation and breeding value prediction using selected data. J Anim Sci 72 (Suppl 1), 147 (Abstr)

Lawlor TJ, Weigel KA, Misztal I (1995) Accounting for age and stage of lactation at time of classification in genetic evaluations of type trait. J Dairy Sci 78 (Suppl 1), 156

Misztal I (1997) Estimation of variance components with large-scale dominance models. $J$ Dairy Sci 80, 965-974

Misztal I, Fernando RL, Grossman M, Lawlor TJ, Lukaszewicz M (1995) Dominance and epistatic effects in genetic evaluation. Animal Sci Papers Reports 13, 251-266

Misztal I, Lawlor TJ, Fernando RL (1997) Dominance models by Method R for stature in Holsteins. J Dairy Sci 80, 975-978.

Misztal I, Lawlor TJ, Short TH, VanRaden PM (1992) Multiple-trait estimation of variance components of yield and type traits using an animal model. J Dairy Sci 75, 544-551

Reverter A, Golden BL, Bourdon RM (1994) Method R variance components procedure: application on the simple breeding value model. J Anim Sci 72, 2247-2253

Rodriguez-Almeida FA, Van Vleck LD, Wilham RL, Northcutt SL 1995. Estimation of non- additive genetic variances in three synthetic lines of beef cattle using an animal model. J Anim Sci 73, 1002-1011

Snelling WM (1994) Genetic analyses of stayability measures of beef females. Ph D Dissertation Colorado State Univ, Fort Collins

Thompson JR, Lee KL, Freeman AE, Johnson LP (1983) Evaluation of a linearized type appraisal system for Holstein cattle. J Dairy Sci 66, 325-331

VanRaden PM (1992) Accounting for inbreeding and crossbreeding in genetic evaluation of large populations. J Dairy Sci 75, 3136-3144

VanRaden PM, Lawlor TJ, Short TH, Hoeschele I (1992) Use of reproductive technology to estimate variances and predict effects of gene interactions. J Dairy Sci 75, 2892-2901 